Association for Information Systems AIS Electronic Library (AISeL)

AMCIS 2002 Proceedings

Americas Conference on Information Systems

(AMCIS)

December 2002

\title{
PREDICTING E-SERVICES ADOPTION: A PERCEIVED RISK FACETS PERSPECTIVE
}

Mauricio Featherman

Washington State University

Paul Pavlou

University of Southern California

Follow this and additional works at: http://aisel.aisnet.org/amcis2002

\section{Recommended Citation}

Featherman, Mauricio and Pavlou, Paul, "PREDICTING E-SERVICES ADOPTION: A PERCEIVED RISK FACETS PERSPECTIVE" (2002). AMCIS 2002 Proceedings. 145.

http://aisel.aisnet.org/amcis2002/145

This material is brought to you by the Americas Conference on Information Systems (AMCIS) at AIS Electronic Library (AISeL). It has been accepted for inclusion in AMCIS 2002 Proceedings by an authorized administrator of AIS Electronic Library (AISeL). For more information, please contact elibrary@aisnet.org. 


\title{
Predicting E-Services Adoption: A Perceived Risk Facets Perspective
}

\author{
Mauricio S. Featherman \\ College of Business \& Economics \\ Washington State University \\ mauricio@cbe.wsu.edu
}

\author{
Paul A. Pavlou \\ Marshall School of Business \\ University of Southern California \\ pavlou@marshall.usc.edu
}

\begin{abstract}
Internet-delivered e-services are increasingly being made available to consumers; however, little is known about how they are evaluated for potential adoption. Past research has focused primarily on the positive utility gains attributable to information technology adoption. This research extends that research approach to include measures of potential negative utility (losses) attributable to e-service adoption. Drawing from Perceived Risk Theory, specific risk facets were operationalized, integrated, and empirically tested within the Technology Acceptance Model to propose an e-services adoption model. Results indicate that e-services adoption is adversely affected primarily by performance-based risk perceptions, while perceived ease of use of the eservice reduces risk perceptions. The paper discusses the implications of integrating risk into the proposed eservices adoption model.
\end{abstract}

\section{Introduction}

E-services are interactive software based information systems received via the Internet. They have been referred to as "assets information, business processes, computing resources, applications - made available via the Internet as a means of driving new revenue streams and creating efficiencies." E-services are important in business to consumer (B2C) e-commerce because they represent ways to provide on-demand solutions to customers strengthening customer-service provider relations, creating transactional efficiencies and improving customer satisfaction (Ruyter et al. 2001). Prominent examples of e-services include integrated trip planning, on-line banking and financial portfolio management.

Consumers have shown reluctance to complete online transactions (Hoffman et al. 1999), primarily due to risk concerns (Jarvenpaa et al. 1999, Pavlou 2001). Therefore, perceived risk is posited as a prominent barrier of consumer acceptance of eservices in an e-commerce environment. Consumer perceptions of risks inherent in product adoption and usage have been studied for many years (Bauer 1967, Dowling and Staelin 1994). This immense literature on perceived risk however has not been applied to the relatively new e-services context in an attempt to better predict evaluation and adoption. Toward this end, this study employs elements from the perceived risk literature to predict consumer adoption of e-services. The perceived risk variable is first modeled as a singular variable then decomposed into its sub-facets, as theorized by Cox (1967). In that way, insight may be gained as to which risk facets are salient for potential consumers of e-services.

It is important to distinguish the difference between conducting basic purchase transactions and adopting e-services. The e-service adoption decision is essentially different from most typical e-commerce purchases, as they create a longer-term relationship between the consumer and service provider. There is more at stake for the consumer as the importance of the interaction is more prominent; hence, the adoption decision is more complex. According to Koller (1998), the degree of importance of the situation determines the potential effect of risk. Given that the adoption of e-services is an important decision for most consumers, the role of risk is likely to become prominent. Hence, even if e-services are an e-commerce application to which some adoption models

${ }^{1}$ http://www.hp.com/solutions1/e-services/ (Accessed 3/9/02). 
exist (Pavlou, 2001), it requires a distinct conceptualization. This study focuses on the role of perceived risk on influencing adoption intentions of e-services.

While e-services are convenient and create efficiencies for their users, little is understood about how consumers evaluate them for adoption. Gauging e-service performance quality and the potential utility of the service (perceived usefulness) is a difficult task for consumers, especially given the newness of the online environment. The Technology Acceptance Model (TAM) (Davis 1989) has been utilized in many online contexts to gauge user perceptions of system use, and the probability of adopting an online system (Gefen and Straub, 2000, 2002; Pavlou, 2001, Moon and Kim, 2001; Teo, Lim, \& Lai, 1999). Since TAM has been applied to eCommerce transactions, it may aid our understanding of e-service adoption. This study integrates the risk literature with the basic TAM variables (perceived usefulness and perceived ease of use) to propose a comprehensive model of e-services adoption. In summary, this research seeks to better understand the e-service adoption process by modeling the perceived risk construct within TAM. To empirically validate the proposed model, we chose the context of electronic bill payment (e-billpay) services, which is the electronic receipt and payment of bills using an e-service delivered via the Internet. The research may also benefit practitioners as increased understanding of consumer perceptions can be used to devise risk-reducing strategies to encourage service adoption, especially in the emerging area of electronic payments.

The research is deemed important from an academic perspective as it includes measures of negative utility (perceived usage risks) into the existing positive utility oriented adoption model. Hence, this study enlarges the scope of the e-services adoption decision to include both risks (potential negative utility) and perceived usefulness (potential positive utility). In summary, this research seeks to provide empirical insight into the following two research questions:

- How important are risk perceptions to the overall e-services adoption decision?

- What types of risk are salient and therefore important to the consumer of e-services?

The paper proceeds with the following sections. First, a brief review of the Perceived Risk and Technology Acceptance literature results in a tentative research model. Exploratory research models are presented in experiment $\# 1$ to modify the initial model and introduce a revised model, which is then confirmed in experiment \#2. The paper concludes by discussing the implications of the resulting e-services adoption model.

\section{Conceptual Development}

\section{Perceived Risk}

Perceived risk (PR) is commonly thought of as an uncertainty regarding possible negative consequences of using a product or service. It has formally been defined as "a combination of uncertainty plus seriousness of outcome involved" (Bauer 1960, 1967), and "the expectation of losses associated with purchase and acts as an inhibitor to purchase behavior" (Peter \& Ryan 1976). PR has been captured with likert scales measuring the perception of dangerous events occurring or the presence of the attribute in the service. Alternately it has been measured using an expectancy * value methodology typically multiplying either probability of loss, exposure or danger (uncertainty component) by the cost or importance of that potential loss or exposure (severity component). Following these descriptions, we define perceived risk as " the potential for loss in the pursuit of a desired outcome of using an e-service."

PR enters the information systems adoption decision when circumstances of the decision create (a) feelings of uncertainty, (b) discomfort and/or anxiety (Dowling and Staelin, 1994), (c) conflict aroused in the consumer (Bettman, 1973), (d) concern, (e) psychological discomfort (Zaltman and Wallendorf, 1983), (f) making the consumer feel uncertain (Engel, Blackwell \& Miniard 1986), (g) pain due to anxiety (Taylor 1974), (h) and cognitive dissonance (Festinger 1957, Germunden 1985). The cognitive dissonance arises from the evaluation of the product as having costs and benefits, risks, and utility. For the current research context, the utility gains are potential increased efficiencies, cost savings, and fiscal control, while the risks include possible task performance related problems and the uncertainty of the Internet as an unsecured communications medium.

\section{Facets of Perceived Risk}

Cox (1967) identified two major categories of perceived risk, (a) performance and (b) psychosocial. He broke performance into three types (i) economic, (ii) temporal, (iii) effort; and broke psychosocial into two types - (i) psychological and (ii) social. 
Cunningham (1967) further typified perceived risk as having six dimensions-(1) performance, (2) financial, (3) opportunity/time, (4) safety, (5) social, and (6) psychological loss. A rich literature stream exists that supports the usage of these risk facets to understand consumer product and service evaluations and purchases. Pilot tests of the current study indicted that a combined perceived risk variable was useful to better understand e-services adoption. The pilot test sample did not consider e-services adoption as incurring any threat to human life; therefore measures of safety risk were not included in this study.

This research tests the significance of a seventh risk facet, perhaps salient for the research context and category of information system it represents. Pilot test results have indicated subjects' concern for the theft of their private information, or simply it's misuse by the company collecting it. Members of a focus group drawn from the same population studied here have also referred to concerns for the loss of privacy of personal financial information as an "identity-theft". Measures of privacy risk were gathered and modeled as a deterrent to utility evaluations and the adoption choice. The proposed risk facets are defined in Table 1. Based on the proposed conceptualization, for this context we propose:

\section{H1: Perceived risk comprises the facets of (1) performance, (2) financial, (3) time, (4) psychological, (5) social, (6) privacy, and (7) overall risk.}

\section{Technology Acceptance}

TAM was designed to gather evaluative measures of information system quality and suitability to job requirements, and thereby enable predictions of acceptance and usage. Davis wrote "The goal of TAM is to provide an explanation of the determinants of computer acceptance that is general, capable of explaining user behavior across a broad range of end-user computing technologies and user populations" (Davis et. al. 1989 p. 985). TAM posits that an attitude toward using an information system is based on two primary antecedent variables - perceived usefulness, and perceived ease of use. These are similar to Bandura's (1982) outcome judgment, and self-efficacy. Software perceived as helpful in performing important tasks and easy to use are evaluated more highly and often deemed desirable. An excellent theoretical review of the model was provided when the model was expanded (Venkatesh \& Davis 2000), and the reader is encouraged to use that source for a more in-depth literature review. While the expanded TAM would provide a richer research framework, and in fact data was thusly gathered, the current research utilizes the more parsimonious model (perceived usefulness and perceived ease of use as predictors of adoption intention) to better focus on interactions with the introduced perceived risk variable.

Table 1. Description and Definition of Perceived Risk Facets

\begin{tabular}{|l|l|}
\hline \multicolumn{1}{|c|}{ Perceived Risk Facet } & \multicolumn{1}{c|}{ Description - Definition } \\
\hline 1) Performance Risk & $\begin{array}{l}\text { "The possibility of the product malfunctioning and not performing as it was designed and } \\
\text { advertised and therefore failing to deliver the desired benefits." (Grewal et al., 1994) }\end{array}$ \\
\hline 2) Financial Risk & $\begin{array}{l}\text { "The potential monetary outlay associated with the initial purchase price as well as the } \\
\text { subsequent maintenance cost of the product" (ibid). The current financial services research } \\
\text { context expands this facet to include the recurring potential for financial loss due to fraud. }\end{array}$ \\
\hline 3) Time Risk & $\begin{array}{l}\text { Consumers may lose time when making a bad purchasing decision by wasting time researching } \\
\text { and making the purchase, learning how to use a product or service only to have to replace it if } \\
\text { it does not perform to expectations. }\end{array}$ \\
\hline 4) Psychological Risk & $\begin{array}{l}\text { Potential loss of self-esteem (ego loss) and ego frustration based on feelings about oneself. } \\
\text { Consumers feel unwise if they experience a non-performing product and may experience } \\
\text { feelings of harm to their self-image from the frustration of not achieving their buying goals. }\end{array}$ \\
\hline 5) Social Risk & $\begin{array}{l}\text { Potential loss of status in one's social group as a result of adopting a product or service, } \\
\text { looking foolish or untrendy. }\end{array}$ \\
\hline 6) Privacy Risk & $\begin{array}{l}\text { Potential loss of control over personal information, such as when information about you is } \\
\text { used without your knowledge or permission. The extreme case is where a consumer is } \\
\text { "spoofed" meaning a criminal uses their identity to perform fraudulent transactions. }\end{array}$ \\
\hline 7) Overall Risk & A measure of perceived risk when all criteria are evaluated together. \\
\hline
\end{tabular}

The following hypotheses are drawn from the above literature review. Perceived risk is seen as negative utility and therefore is proposed as moderating usefulness (positive utility) evaluations of e-services. 


\section{H2: E-services perceived risk adversely affects perceptions of system utility and inhibits adoption intention}

\section{H3: E-services privacy risk adversely affects perceptions of system utility and adoption intention
H4: Perceptions of e-service ease of use ascertained from hands-on trial significantly reduces perceived risks of usage

The proposed model and research hypotheses are presented in figure \#1 below. Perceived risk has been modeled as both a composite variable and decomposed into its sub-facets. Once the proposed model has been studied, the most important risk facets can be identified and risk-reducing strategies can be designed to counteract them.

\section{Research Methodology}

This research follows Featherman (2001) and Pavlou (2001) and incorporated a measure of the perceived risk variable into TAM. Two computer lab based experiments were performed each drawing a different sample from the population of undergraduate business students of a large university. While the subjects were students and therefore a homogeneous population they did represent an important target market for the e-billpay service and are considered appropriate for experimental-based theory development. The initial experiment $(\mathrm{N}=214)$ was used to test the psychometric properties of the indicants and research model. A second experiment $(\mathrm{N}=157)$ was used to confirm the relationships found amongst the risk facets and the research model's nomological validity.

Both experiments used the same methodology. Subjects were briefed on the e-billpay product category, then read brand information and performed a 25 minute "shopping trial" using an interactive, demonstration software hosted on a vendor's website. After the trial, subjects were asked to evaluate the brand they were exposed to by completing a paper and pencil survey that utilized 7-point likert and semantic differential scales. Items to capture the perceived risk facets, e-service ease of use, and usefulness were gathered, as well as measures of intention to adopt the e-billpay service given the proper facilitating conditions were available.

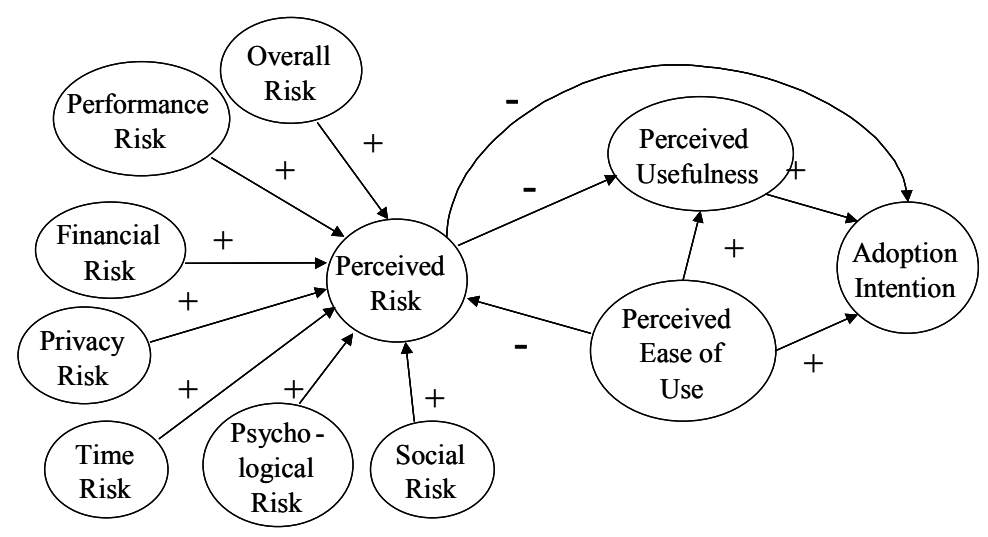

Figure 1. Research Model
Experimental results were evaluated as follows. Variable psychometric properties were measured using Chronbach's alpha and a first order confirmatory factor analysis. Next a second order confirmatory factor analysis was performed to measure the relative importance of each risk facet. Next the higher order perceived risk variable was included into the research model and path weights and overall fit to the data was tested using a structural equation modeling. Analysis continued with a deeper evaluation of the relationship amongst risk facets. TAM's two criterion variables were regressed directly onto the risk facets to assess collinearity, and a final structural model was measured to confirm regression findings and refine the research model.

While experiment \#1's results confirmed the pilot test finding that a composite perceived risk variable negatively affected TAM's criterion variables, the development of a model with a hierarchical relationship amongst the perceived risk facets was data-driven and therefore deemed exploratory. Experiment \#2 was therefore performed using a separate sample from the same population, and analyzed with identical methodology in an attempt to confirm the findings of experiment $\# 1$.

In all analyses two-tailed tests are employed with the following notation utilized: * signified a $\mathrm{p}$ value of $<.05, * *$ signified a $\mathrm{p}$ value of $<.01$ and $* * *$ signified a $\mathrm{p}$ value of $<.001$. 


\section{Experiment \#1 Results}

Results shown in Table 2 below indicated that each risk facet exhibited strong internal reliability as indicated by Chronbach's alpha scores of .80 or higher. Group means for each risk facet measured the probability of the e-billpay service having and therefore causing the specified risk. As compared to the general population, the sample population of university students was younger, more computer literate, and more comfortable with Internet based transactions. These combined factors likely reduced perceived risk levels as compared to the general population. While this sample may not have perceived high levels of e-service inherent risk, each risk facet was nevertheless rated as very important. The importance (value) portion of the expectancy-value measurement has been proposed as being a better indicator of perceived risk as many consumers are not able to accurately gauge probability of risk.

Items were added to TAM's two criterion scales to strengthen them and enable structural modeling. The Perceived Usefulness scale included items that were used in the original TAM scale, and repeated in Moore and Benbasat's (1991) Relative Advantage scale, but dropped from the shorter 2000 TAM operationalization. Additionally, three pre-tested original items were added to the Adoption Intention scale to enable structural modeling. Table 2 below indicates that these additions did not harm the internal reliability of either variable. Support was also provided for the inclusion of a privacy risk facet for e-services adoption research. It exhibited the highest group mean for both studies and ranked only behind financial risk in importance.

Table 2. Psychometric Properties and Descriptive Measures of Research Variables

\begin{tabular}{|l|c|c|c|c|}
\hline \multirow{2}{*}{$\begin{array}{l}\text { Measured } \\
\text { Variables }\end{array}$} & \multicolumn{5}{|c|}{ Experiment \#1 } \\
\cline { 2 - 5 } & Alpha & \# Items & $\overline{\mathbf{X}}$ & Importance \\
\hline Time Risk & .80 & 3 & 2.96 & 5.26 \\
\hline Psychological Risk & .87 & 2 & 2.36 & 3.63 \\
\hline Privacy Risk & .86 & 2 & 3.79 & 6.16 \\
\hline Financial Risk & .84 & 2 & 2.71 & 6.22 \\
\hline Performance Risk & .81 & 4 & 3.37 & 5.98 \\
\hline Social Risk & .82 & 2 & 1.98 & 3.17 \\
\hline Overall Risk & & 1 & 3.35 & \\
\hline Ease of Use & .87 & 4 & 5.42 & \\
\hline Usefulness & .95 & 10 & 5.12 & \\
\hline Adoption Intention & .97 & 5 & 4.38 & \\
\hline
\end{tabular}

Next a first order confirmatory factor analysis (CFA) was performed using AMOS ver. 4 to measure the ability of the indicants to measure the theorized risk facets. The model combined items from the time and performance risk facets to improve power. The CFA model exhibited excellent maximum likelihood estimated fit indices with the $X^{2} / \mathrm{df}$ ratio of 1.73 , with GFI $=.94$, NFI $=.95$ and RMSEA $=.059$. These indices indicate that only $5.9 \%$ of the variance in the data was unexplained by the risk facets and in general the model fit the data very well $\left(X^{2} / \mathrm{df}\right.$ ratio $<2.0$, GFI and NFI $\left.>.90\right)$. Table 3 below indicates that the majority of the variance in each indicant was explained by the theoretical construct.

A CFA-derived correlation matrix of the risk facets shown in table 3 below supported the Cox (1967) proposition that perceived risk has two main categories, performance related and psychosocial. This is evidenced by the financial, time, privacy and performance facets strong inter-correlations, as do the social and psychological facets.

As perceived risk has been theorized as comprising all of these facets, a second order CFA model was next analyzed. Results presented in figure 2 below were very promising, indicated an excellent fit to the data, and largely supported H1. The lone exception was that the model explained only $9 \%$ of the variation for social risk. For this sample and context then the social risk attached to e-services adoption were neither important nor salient. For this reason social risk was dropped from further analysis. This sample appears to have focused on the performance-related risks during system evaluation and adoption decision-making. This second order perceived risk variable was next positioned within TAM to test the remaining research hypotheses. Results are shown in figure 3 below. 
Table 3. Experiment \#1 First-Order CFA Psychometrics For Risk Facet Variables $\%$ of Variance Explained CFA Derived Correlation Matrix

\begin{tabular}{|c|c|c|c|c|c|c|c|c|c|c|}
\hline Indicant & Factor 1 & Factor 2 & Factor 3 & Risk Facet & $\begin{array}{l}\text { Perfor- } \\
\text { mance }\end{array}$ & Financial & Psych & Time & Privacy & Social \\
\hline Performance Risk & .690 & .527 & .627 & Performance & 1 & & & & & \\
\hline Financial Risk & .653 & .755 & & Financial & .830 & 1 & & & & \\
\hline Psych Risk & .780 & .825 & & Psych & .477 & .515 & 1 & & & \\
\hline Time Risk & .431 & .536 & & Time & .982 & .858 & .573 & 1 & & \\
\hline Privacy Risk & .816 & .663 & & Privacy & .833 & .749 & .312 & .854 & 1 & \\
\hline Social Risk & .647 & .740 & & Social & .273 & .332 & .749 & .418 & .154 & 1 \\
\hline
\end{tabular}

Results indicated reasonably acceptable fit indices for the smallish sample size. Each TAM construct was measured by at least three indicants, and the items for the risk facets were combined to define six indicants for the second order perceived risk variable. Results supported hypothesis \#2 and \#3 in that consumer concerns for potential financial losses, system performance problems, loss of time and privacy breaches were salient during e-service evaluation and adoption decision making. Hypotheses \#4 was also supported as indicated by the significant path from perceived ease of use to perceived risk. This suggests that e-service software that is easy to use during system trial reduces risk concerns. This indirect path is plausible as expected risks inherent in service performance are shaped in part by the usability of the software interface. If the user cannot easily manipulate the software they portend further performance problems, expected service performance becomes increasingly uncertain and therefore perceived risk increases. This path also indicates that as the e-service increases in usability expected performance risks reduce. This path is interpreted as an important theoretical contribution for the importance of the ease of use variable, whose effects are often minimized by the collinear usefulness variable.

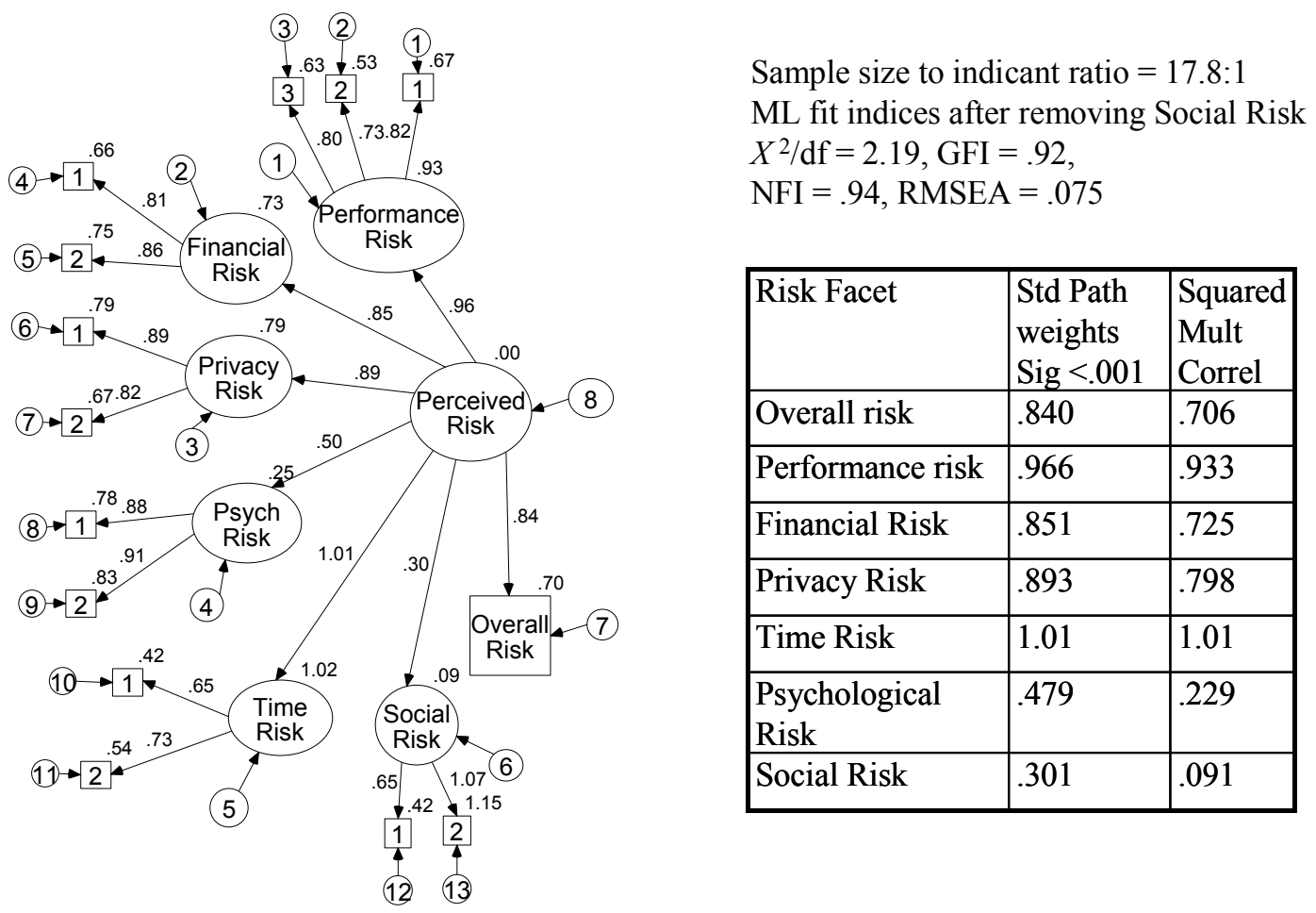

Figure 2. Experiment \#1 Second Order CFA Perceived Risk Facets Model

While empirical support suggests the inclusion of perceived risk into TAM when the context is an e-service, the question remains, which specific risk facets, were most important to the potential consumers? Cox (1967) indicated that performance and psychosocial risk were the two base risk facets, however for this sample and context social risk was not important, and was dropped from further analysis. Psychological risk concerns were also less important that the performance related facets, however as this affect-based measure of personal frustration was deemed interesting, it was included in further analysis. The measure of overall perceived risk was not deemed specific enough for this analysis and was also dropped. 


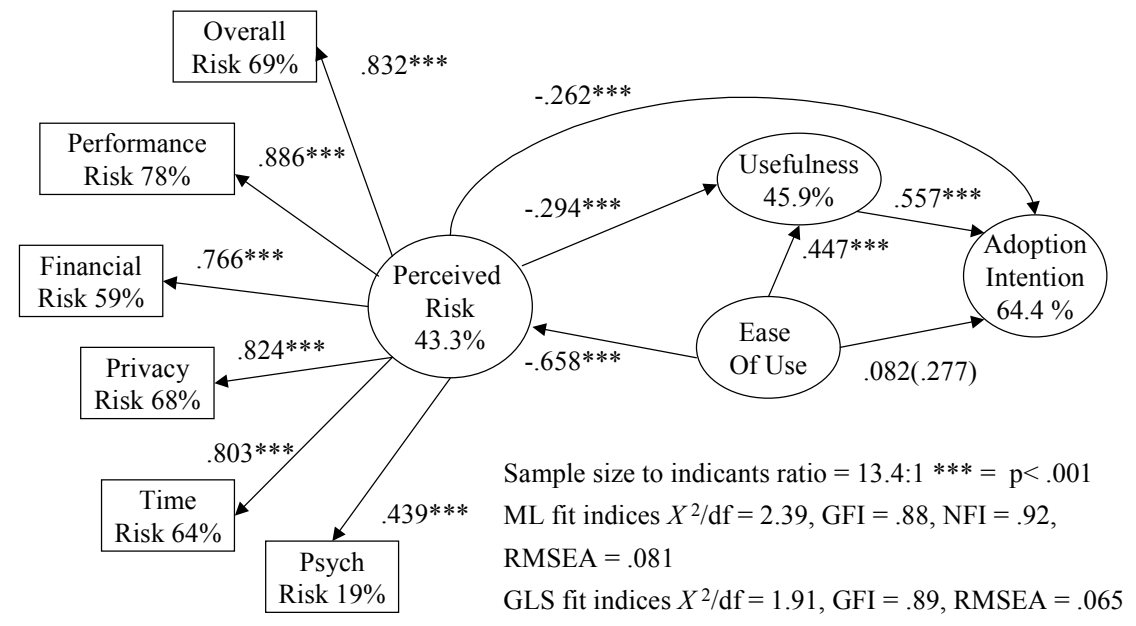

Figure 3. Experiment \#1 Research Model Results
Further analysis of the correlation matrices reported multicollinearity amongst the financial, privacy, time and performance risk facets (indicated by correlations of .70 or higher). This multicollinearity was also evident by the variance inflation factor scores (VIF) of $>2.0$ reported in table 4 below when regressing TAM's criterion variables onto the risk facets. These SPSS ver. 11-based results indicated that primarily the loss of time and concerns for e-service performance risk inhibited usefulness evaluations and adoption intentions. The models were confirmed with a first order model utilizing AMOS ver 4.0. The multicollinearity indicants suggested the need for a further refinement of the second order model to investigate the relationship amongst psychological, privacy and financial risk, and in turn their affect on the collinear time and performance risk facets. This level of analysis was theoretically motivated, representing a refinement of perceived risk theory.

This hierarchical model shown below in figure \#4 is supported by previous findings. As mentioned, Cox (1964) originally found that performance risk was a major category of perceived risk from which sprang time, and economic concerns. Cox's taxonomy was created in a different era, and perhaps busy lifestyles have placed an increased premium on our time which in turn increases its' importance in purchase decisions. Bellman et al. (1999) reported that time is an important variable and found it the significant predictor to online buying behavior. Their research found that "harried" consumers with less time were more likely to purchase over the Internet in order to save time. The current research similarly proposes that consumers are very time oriented and concerned about "wasting time" implementing, learning how to use, and troubleshooting a new e-service. These time-conscious consumers likely guard against the possible loss of time, and are less likely to adopt the e-service that they consider has high switching, setup and maintenance costs.

The research model was therefore modified to emphasize the salience of performance and time concerns and is shown in figure \#4 below. Fit indices while suffering from the small sample to indicant ratio (10.7:1), supported the model refinement and show an acceptable fit to the data, with only five percent of the variance in the model not explained by the indicants when using the GLS estimation method. GLS has been previously shown to perform better than maximum likelihood (ML) estimation for small samples (Hu and Bentler 1995). The sample to indicant ratios shrank as each risk facet included was measured using all indicants shown in figure 2 (minus the social and overall risk variables). Both ML and GLS derived fit indices are reported for comparison purposes.

Table 4. Experiment \#1 - Regression of TAM Criterion Variables on Perceived Risk Facets Perceived Usefulness

\begin{tabular}{|l|c|c|c|}
\hline \multicolumn{2}{|l|}{ Regression Results $\left(\mathrm{R}^{2}=.369\right)$} & $\begin{array}{c}\text { SEM Results } \\
\left(\mathrm{R}^{2}=.457\right)\end{array}$ \\
\hline $\begin{array}{l}\text { Predictors - } \\
\text { Risk Facets }\end{array}$ & $\begin{array}{c}\text { Beta } \\
\text { Coeff. }\end{array}$ & VIF & $\begin{array}{c}\text { Std .Reg. } \\
\text { Weights }\end{array}$ \\
\hline Time & $-.355^{* * *} *$ & 2.23 & $-.339 * * *$ \\
\hline Psychological & .092 & 1.38 & $.100^{*}$ \\
\hline Privacy & .118 & 2.29 & $.181 * *$ \\
\hline Financial & -.007 & 2.39 & -.059 \\
\hline Performance & $-.427 * * *$ & 2.83 & $-.544 * * *$ \\
\hline
\end{tabular}
Adoption Intention

\begin{tabular}{|l|c|c|c|}
\hline \multicolumn{3}{|l|}{ Regression Results $\left(\mathrm{R}^{2}=.392\right)$} & $\begin{array}{c}\text { SEM Results } \\
\left(\mathrm{R}^{2}=.391\right)\end{array}$ \\
\hline $\begin{array}{l}\text { Predictors - } \\
\text { Risk Facets }\end{array}$ & $\begin{array}{c}\text { Beta } \\
\text { Coeff. }\end{array}$ & VIF & $\begin{array}{c}\text { Std .Reg. } \\
\text { Weights }\end{array}$ \\
\hline Time & $-.259 * *$ & 2.23 & $-.300 * * *$ \\
\hline Psychological & .036 & 1.38 & .082 \\
\hline Privacy & -.108 & 2.29 & -.022 \\
\hline Financial & .039 & 2.39 & .037 \\
\hline Performance & $-.380 * * *$ & 2.83 & $-.540 * * *$ \\
\hline
\end{tabular}




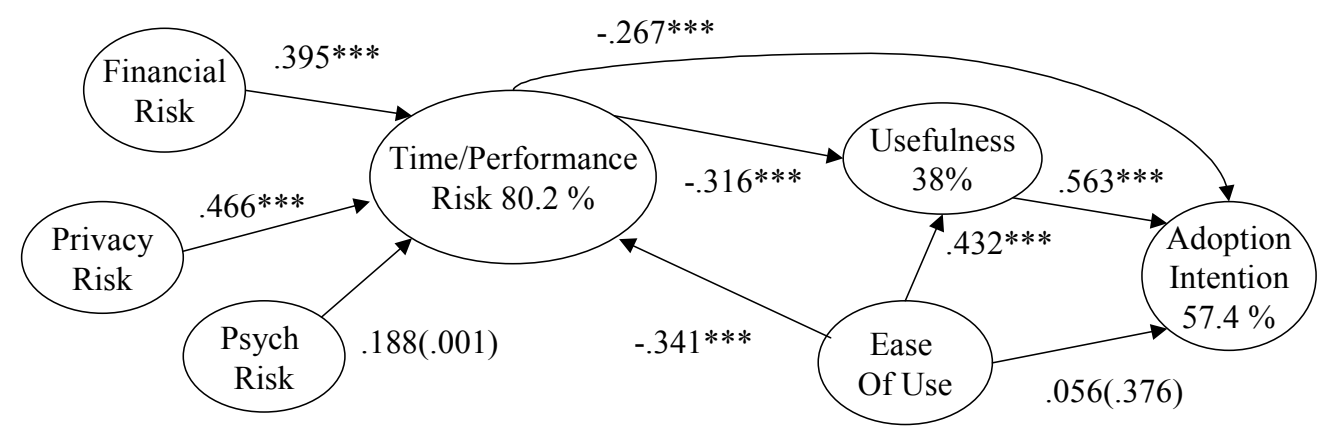

$\mathrm{N}=214$, with 20 indicants $=10.7: 1$ ratio

ML Indices $X^{2} / \mathrm{df}=2.55, \mathrm{GFI}=.83, \mathrm{NFI}=.88 \mathrm{RMSEA}=.085$

GLS Indices $X^{2} / \mathrm{df}=1.53, \mathrm{GFI}=.89$, RMSEA $=.05$

$* * *=p<.001$, all other standardized path weights listed with significance listed in parentheses

\section{Figure 4. Experiment \#1 Final Structural Model}

The model suggests that concerns for a poorly performing e-service that creates a loss of time, are primarily based on financial and privacy risk concerns, and to a less extent psychological risk. The time/ performance risk variable fully mediated the effects of financial, privacy and psychological risk on the downstream TAM criterion variables. This finding then provided only partial support for hypotheses \#3. Privacy risk indirectly affected TAM's criterion variables, and rather contributed to time/performance risk. The model also suggests that consumers concern for a loss of personal information or "identity theft" was the strongest performance risk.

In summary for this sample and context, empirical evidence supported the inclusion of a single perceived risk variable into TAM and also supported the inclusion of the individual time, performance, financial, privacy and psychological risk facets. Support for each hypothesis was provided. Furthermore, a hierarchical structure may be evident within the risk facets, with financial, privacy and time risk affecting the more salient performance and time risk concerns. These assertions and models need to be confirmed with a different data set however and therefore the second experiment was administered. Those results of that confirmatory study are now presented.

\section{Experiment \#2Results}

A shortcoming of the first experiment was the limited number of items per risk facet; therefore items were added to each variable. While Chronbach's alpha scores listed in table 5 below indicate the variables were strengthened, the higher number of indicants unfortunately accentuated the small sample to indicant ratio problem as evidenced by a corresponding reduction in fit indices shown below. A second sample was drawn from the same undergraduate university population and the same experimental methodology was administered. In this iteration however, a third of the sample tested and evaluated a second e-billpay brand. The two trials were identical with the only appreciable difference attributable to brand recognition and perhaps color of interface (green vs. blue). Between groups t-tests indicated no significant difference in group mean risk levels for any risk facet, or TAM variable and therefore the results were pooled. Data was gathered for social and overall risk for comparative purposes.

Table 6 reports a rise in the percentage of variance explained by the risk facets for each indicant. The correlation matrix indicates a similar collinearity pattern amongst the risk facets as exhibited in experiment \#1. The first order CFA model was acceptable with maximum likelihood estimated fit indices recorded as $X^{2} / \mathrm{df}=1.97$, GFI $=.86, \mathrm{NFI}=.93, \mathrm{RMSEA}=.079$. Due to the small subject to indicant ratio the model was reestimated using general least squares (GLS) estimation reported with the fit indices improving to $X^{2} / \mathrm{df}=1.40, \mathrm{GFI}=.89$ and $\mathrm{RMSEA}=.05$, again indicating the risk facets fit the data well as only five percent of the variance in the indicants was unexplained. The second order CFA model shown in figure 5 below supported H1and again suggested the removal of social risk, as the model explained only $7 \%$ of its variance. The first-order CFA estimates reported above therefore were reported after removing the social risk variable.

As in experiment \#1 the risk facets proved valid and reliable and therefore the research model could again be tested with the second sample. Model path weights, percentage of variance explained, and fit indices are shown in figure 6. 
Table 5. Experiment \#2 - Psychometric Properties and Descriptive Measures of Research Variables

\begin{tabular}{|l|c|c|c|c|}
\hline \multirow{2}{*}{$\begin{array}{l}\text { Measured } \\
\text { Variables }\end{array}$} & \multicolumn{4}{|c|}{ Experiment \#2 } \\
\cline { 2 - 5 } & Alpha & \# Items & $\overline{\mathbf{X}}$ & Importance \\
\hline Time Risk & .83 & 4 & 2.87 & 4.81 \\
\hline Psychological Risk & .79 & 3 & 2.36 & 3.45 \\
\hline Privacy Risk & .88 & 3 & 3.98 & 5.77 \\
\hline Financial Risk & .92 & 6 & 3.55 & 5.89 \\
\hline Performance Risk & .93 & 7 & 3.31 & 5.50 \\
\hline Social Risk & .92 & 2 & 1.84 & 2.95 \\
\hline Overall Risk & .89 & 2 & 3.77 & 5.71 \\
\hline Ease of Use & .89 & 4 & 5.53 & \\
\hline Usefulness & .94 & 10 & 5.35 & \\
\hline Adoption Intention & .92 & 5 & 4.37 & \\
\hline
\end{tabular}

Table 6. Experiment \#2 First-Order CFA Psychometrics For Risk Facet Variables

\section{$\%$ of Variance Explained CFA Derived Correlation Matrix}

Indicant

Performance Risk

Financial Risk

Psych Risk

Time Risk

Privacy Risk

Social Risk

Overall Risk
Factor 1 Factor 2 Factor 3

.781

.728

.486

.515

.663

.849

.844

$$
\begin{array}{ll}
.834 & .735 \\
.803 & .781 \\
.544 & .654 \\
.938 & .806 \\
.688 & .760 \\
.846 & \\
.746 &
\end{array}
$$

\section{Risk Facet}

Performance

Financial

Psych

Time

Privacy

Overall

Social
Performance

Financial Psych Time Privacy Overall Social

1

$.910 \quad 1$

.619

.740

.856

.883

.256

$$
\begin{aligned}
& .559 \\
& .668 \\
& .877 \\
& .891 \\
& .208
\end{aligned}
$$

$\begin{array}{cc}1 & \\ .575 & 1 \\ .428 & .687 \\ .599 & .777 \\ .753 & .281\end{array}$

.919

.124

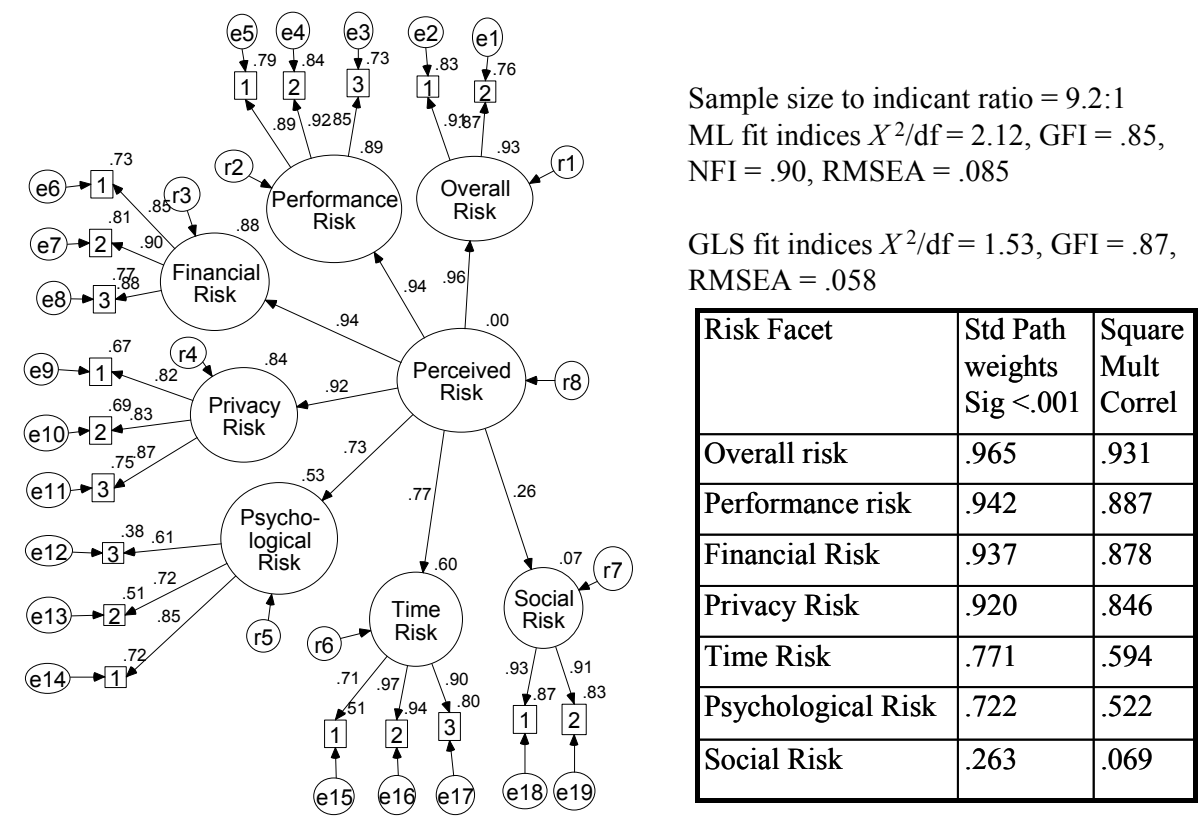

Figure 5. Experiment \#2 Second Order CFA Perceived Risk Facets Model 


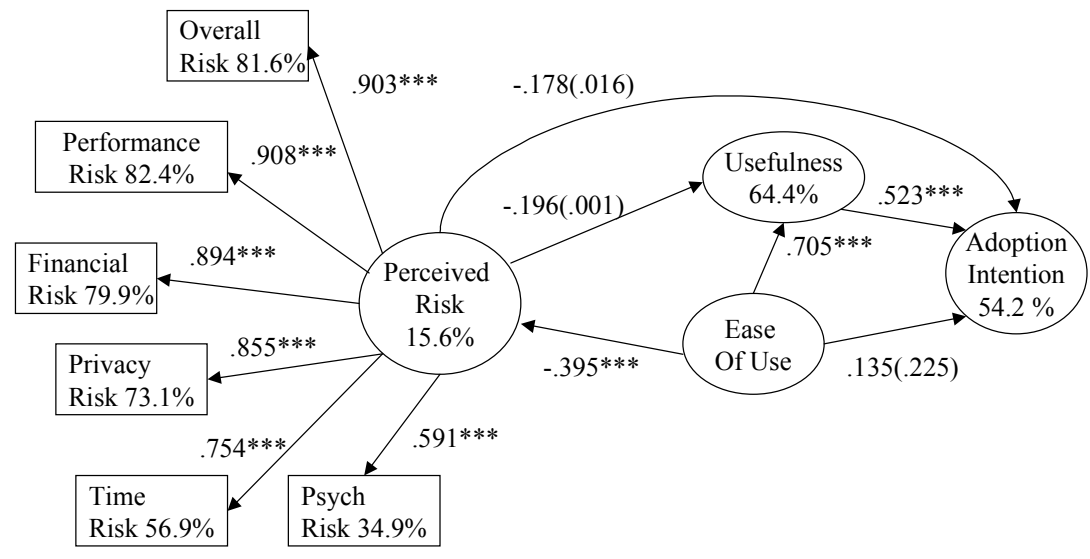

Sample size to indicants ratio $=9.8: 1$,

$* * *=\mathrm{p}<.001, \%=$ percentage of variance accounted for

ML fit indices $X^{2} / \mathrm{df}=2.14, \mathrm{GFI}=.86, \mathrm{NFI}=.91, \mathrm{RMSEA}=.086$

GLS fit indices $X^{2} / \mathrm{df}=1.45, \mathrm{GFI}=.89, \mathrm{RMSEA}=.054$
The research model while containing better measures of each variable, suffered from a smaller sample size and sample to indicant ratio $(<10: 1)$. The fit indices are strong enough however to confirm the research model as again the model accounted for all but $5.4 \%$ of the variance in the data. The decision was again made to drop the overall risk variable to better focus on the more specific risk facets. The possible hierarchical relationship amongst the perceived risk facets was again investigated. The correlation matrix shown in table 6 above and the VIF metric of the regression results in table 7 below again indicated severe multicollinearity amongst the perceived risk facets. These relationships were again disentangled using the refined second order structural model proposed in experiment $\# 1$ and utilized in figure 7 below.

Figure 6. Experiment \#2 Research Model Results

Table 7. Experiment \#2 - Regression of TAM Criterion Variables on Perceived Risk Facets

Perceived Usefulness

\begin{tabular}{|l|c|c|c|}
\hline \multicolumn{3}{|l|}{ Regression Results $\left(\mathrm{R}^{2}=.337\right)$} & $\begin{array}{c}\text { SEM Results } \\
\left(\mathrm{R}^{2}=.494\right)\end{array}$ \\
\hline $\begin{array}{l}\text { Predictors - } \\
\text { Risk Facets }\end{array}$ & $\begin{array}{c}\text { Beta } \\
\text { Coeff. }\end{array}$ & VIF & $\begin{array}{c}\text { Std } \text { Reg. } \\
\text { Weights }\end{array}$ \\
\hline Time & $-.525^{* * *}$ & 2.15 & $-.656^{* * *}$ \\
\hline Psychological & -.096 & 1.61 & -.079 \\
\hline Privacy & .060 & 3.06 & .114 \\
\hline Financial & .178 & 4.04 & .120 \\
\hline Performance & -.192 & 4.33 & $-.171^{* *}$ \\
\hline
\end{tabular}

Adoption Intention

\begin{tabular}{|l|c|c|c|}
\hline \multicolumn{2}{|l|}{ Regression Results $\left(\mathrm{R}^{2}=.237\right)$} & $\begin{array}{c}\text { SEM Results } \\
\left(\mathrm{R}^{2}=.330\right)\end{array}$ \\
\hline $\begin{array}{l}\text { Predictors - } \\
\text { Risk Facets }\end{array}$ & $\begin{array}{c}\text { Beta } \\
\text { Coeff. }\end{array}$ & VIF & $\begin{array}{c}\text { Std .Reg. } \\
\text { Weights }\end{array}$ \\
\hline Time & $-.430 * * *$ & 2.15 & $-.550 * * *$ \\
\hline Psychological & .053 & 1.61 & .049 \\
\hline Privacy & -.065 & 3.06 & -.061 \\
\hline Financial & .126 & 4.04 & .069 \\
\hline Performance & -.161 & 4.33 & $-.128(.096)$ \\
\hline
\end{tabular}

Results suggested the research model's nomological pattern was confirmed for this second sample. All relationships amongst the variables exhibited similar significance and directionality. Support for $\mathrm{H} 2$ was provided by experiment \#2, as consumer's concerns for the perceived risks of e-service adoption inhibited both the perceived usefulness evaluation and adoption intentions. Partial support for $\mathrm{H} 3$ was again provided, wherein privacy risk indirectly reduced system evaluations and adoption intention. The final hierarchical risk facet model indicated that privacy risk functions through the combined time/performance risk. Finally H4 was again supported as perceptions of the e-service's ease of use likely reduced consumer's expected performance uncertainty and therefore risk perceptions.

For the e-services research context ease of use was not a direct antecedent to adoption intention and rather functioned indirectly through usefulness, consistent with previous TAM empirical validations. In both samples however the indirect effect of ease of use on system evaluation and adoption was indicated by its reduction of perceived risk. The ease of use of E-services that are evaluated on-line is important as it can reduce perceptions of service usage risk that concern consumers. 


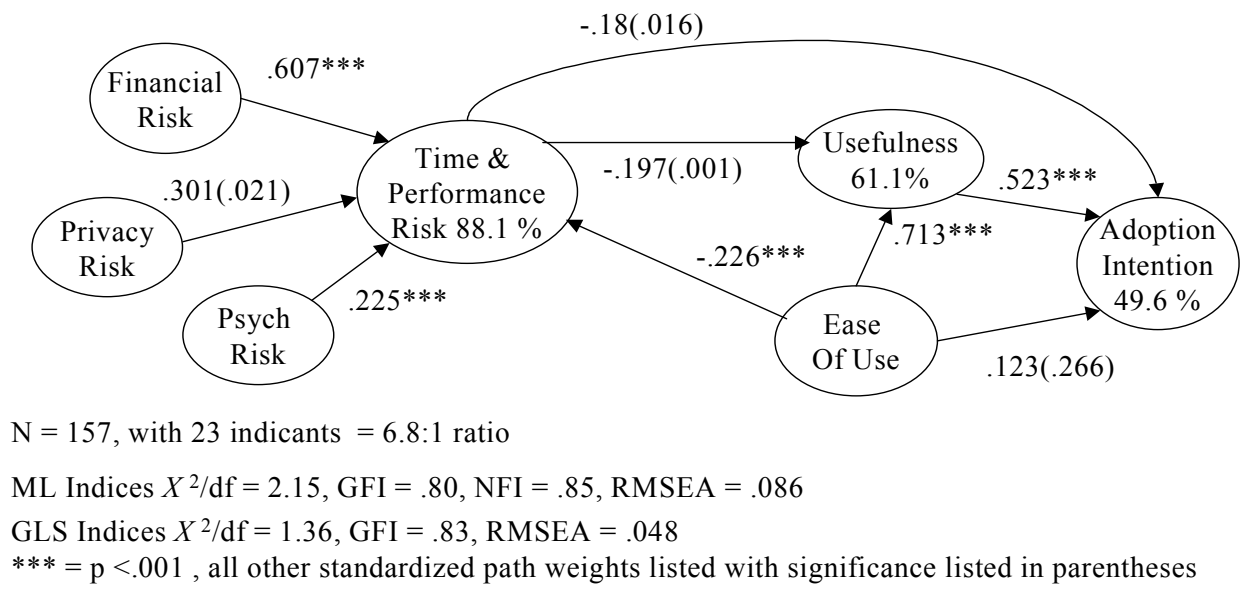

Figure 7. Experiment \#2 Final Structural Model

\section{Discussion}

Previous consumer behavior and information system research has highlighted the importance of perceived risk as an inhibitor to purchasing on the web and adoption of an e-service. The majority of information systems research has focused on the importance of trust and trust building as a prerequisite to e-commerce transactions and development of business relationships. This research looked at the other side of the trust construct, perceived risk and attempted to dive deeper into the construct and provide insight into the facets of perceived risk.

The e-services context was chosen as the importance of this class of information system is growing. Consumer services delivered via the Internet on-demand can provide consumers utility gains as measured in convenience and efficiency. Little was know however how consumers perceive these e-services that are delivered to consumer's homes.

Using the e-billpay service context, empirical evidence was provided for the perceived risk facet measures and support for a privacy risk variable was provided. Evidence for a second-order composite perceived risk variable was found enabling it's testing within the Technology Acceptance Model (TAM). Perceived risk was found to exert a strong inhibiting influence on TAM's criterion variables. This finding encouraged the decomposition of the perceived risk variable into it theorized facets. Performance-related risk facets (time risk, privacy risk, financial risk) proved to be the most salient concerns for this sample and context. Evidence for a risk facet hierarchy was provided as the potential loss of time and a poorly performing e-service emerged as the most salient risk facets with financial, privacy and psychological risk concerns explaining the variance in a combined performance/time risk variable. For this sample and context the perceived social risk of using the e-service was not salient. From the consumer's perspective results may be interpreted as any system that has high switching costs measured in time to set, learn and maintain the software is deemed less useful. Also e-services that may not work properly and process financial payments incorrectly are evaluated more poorly and therefore less likely to be adopted.

Research limitations include the usage of small sample sizes for theory building. While the theorized expected patterns were displayed by the datasets, the overall model fit would have benefitted from larger sample sizes. Also the research is deemed somewhat rudimentary, as the 2000 version of TAM (Venkatesh and Davis) was not utilized. Perceived risk is likely to affect other TAM variables such as subjective norm. This research therefore needs to be extended to include the full Technology Acceptance Model.

Results suggested that many of the important risk facets for the e-services context have been identified. Future research is needed however to discern whether these risk concerns are attributable to the Internet medium or to the e-service provider. Finally this research model should be re-confirmed with different samples and e-services. In summary, this research suggests the inclusion of a performance-based perceived risk variable in e-services adoption research. 


\section{Practical Implications}

This research indicated that while the segment of consumers surveyed in general did not perceive the e-billpay service as having a high level of usage risk, the usage risks perceived were very important to them. Risk perceptions therefore must be controlled in order for e-services adoption to grow. Perceptions of specific risk facets together inhibited system evaluation and adoption, and service providers should devise and publish persuasive information to counter these concerns. It is suggested that service providers provide specific consumer information that directly addresses and counters each of the risk facets presented here. Possibly effective risk reducing strategies are money back guarantees and satisfaction guarantees that can counter performance based risk concerns. More research is needed to determine the level of assurances necessary to allay consumer's product usage concerns for each of the perceived risk facets. As the number of e-services directed at the consumer market grows, the user evaluation experience must be better understood and managed more carefully.

\section{References}

Bandura, A., Social Foundations of Thought and Action: A Social Cognitive Theory, Prentiss-Hall, Englewood Cliffs, New Jersey, 1986.

Bauer, R., “Consumer Behavior as Risk Taking,” in Risk Taking and Information Handling in Consumer Behavior, D. Cox (ed.) Harvard University Press, Cambridge, Mass, 1967.

Bellman, S., Lohse, G., and Johnson, E. "Predictors of Online Buying Behavior," Communications of the ACM (42:12), 1999, pp. 32-38.

Bettman, J. "Perceived Risk and Its Components: A Model and Empirical Test.” Journal of Marketing Reseach, 10, May 1973, pp. 184-190.

Cox, D., Rich, S. "Perceived Risk and Consumer Decision Making-The Case of Telephone Shopping," Journal of Marketing Research, November 1964, pp. 32-39.

Cunningham, S. "The Major Dimentions of Perceived Risk," in Risk Taking and Information Handling in Consumer Behavior, D. Cox. (ed.) Harvard University Press, Cambridge, Mass, 1967

Davis, F. "Perceived Usefulness, Perceived Ease of Use, and User Acceptance of Information Technology," MIS Quarterly, September 1989, pp. 319-340.

Davis, F., Bagozzi, R., Warshaw, P. "User Acceptance of User Technology: A Comparison of Two Theoretical Models," Management Science, 35 1989, pp. 982-1002.

Dowling, G., Staelin, R. “A Model of Perceived Risk and Intended Risk-Handling Activity,” Journal of Consumer Research, 21 June 1994, pp. 119-134.

Engel, J., Blackwell, R., and Miniard, P. Consumer Behavior, CBS College Publishing, New York, 1986.

Featherman, M. "Is Perceived Risk Germane to Technology Acceptance Research?," AMCIS Proceedings, Boston, MA, 2001.

Festinger, L., A Theory of Cognitive Dissonance, Stanford University Press, Stanford CA, 1957.

Gefen, D., Straub, D. "The Relative Importance of Perceived Ease-of-Use in IS Adoption: A Study of eCommerce Adoption," JAIS, (1:8), 2000, pp. 1-20.

Gefen, D., Straub, D. "Managing User Trust in e-Services," e-Service Journal, (2:1), forthcoming 2002

Germunden, H. G. "Perceived Risk and Information Search: A systematic Meta-Analysis of Empirical Evidence," International Journal of Research in Marketing 2, 1985, pp. 79-100.

Grewal, D., Gotlieb, J and Marmorstein, H. "The Moderating Effects of Message Framing and Source Credibility on the PricePerceived Risk Relationship,” Journal of Consumer Research 21, June 1994, pp. 145-153.

Hoffman, D., Novak, T., and Peralta M. "Building Consumer Trust Online," Communications of the ACM, (42:4), 1999, pp. 8085.

Hu, L., Bentler, P., "Evaluating Model Fit” in Structural Equation ModelingConcepts, Issues, and Applications, R. Hoyle (ed.), Sage Publications, Thousand Oaks, CA, 1995

Jarvenpaa, S., and Tractinsky, N. "Consumer Trust in an Internet Store: A Cross-Cultural Validation," Journal of Computer Mediated Communication, (5:2) 1999, pp. 1-35.

Koller, M. "Risk as a determinant of Trust," Basic and Applied Social Psychology, (9: 4), 1988, pp. $265-276$.

Moon, J., Kim, Y. (). "Extending the TAM for a World-Wide-Web Context," Information and Management, 28, 2001, pp. 217230.

Moore, G., Benbasat, I. "Development of an Instrument to Measure the Perceptions of Adopting an Information Technology Innovation." Information Systems Research, (2:3), 1991, pp. 192-222.

Peter, J., Ryan, M. “An Investigation of Perceived Risk at the Brand Level,” Journal of Marketing Research, 13, May 1976, pp. 184-188. 
Ruyter, Ko de, Wetzels, M., and Kleijnen, M. "Customer Adoption of e-Service: An Experimental Study,” International Journal of Service Industry Management, (12:2), 2001, pp.184-207

Taylor, J. "The Role of Risk in Consumer Behavior." Journal of Marketing 38, April 1974, pp. 54-60.

Teo, S., Lim, V., and Lai, R. "Intrinsic and Extrinsic Motivation in Internet Usage," Omega International Journal of Management Studies, 27, 1999, pp. 25-37.

Venkatesh, V., Davis, F. "A Theoretical Extention of The Technology Acceptance Model: Four Longitudinal Field Studies," Management Science, (46:2): 2000, pp.186-204.

Zaltman, G., Wallendorf, M. Consumer Behavior, Wiley, New York, 1983. 